\title{
DOCÊNCIA, FORMAÇÃO E INOVAÇÃO: PERCURSOS INTERCONECTADOS NA CONFIGURAÇÃO DO CONHECIMENTO PEDAGÓGICO NA EDUCAÇÃO SUPERIOR
}

\author{
TEACHING, TRAINING AND INNOVATION: \\ INTERCONNECTED PATHWAYS IN THE CONFIGURATION OF PEDAGOGICAL \\ KNOWLEDGE IN HIGHER EDUCATION
}
ENSEÑANZA, FORMACIÓN E INNOVACIÓN:
VÍAS INTERRELACIONADAS EN LA CONFIGURACIÓN DEL CONOCIMIENTO DOCENTE EN EDUCACIÓN SUPERIOR

Vera Lucia Pontes dos Santos ${ }^{1}$, Cleide Jane de Sá Araújo Costa ${ }^{2}$

\begin{abstract}
RESUMO
Este artigo analisa o impacto de um curso e atualização profissional à ação pedagógica de professores universitários. O curso representa uma ação do programa de formação docente de uma universidade pública do Nordeste. $O$ estudo tem o interesse de saber: como a formação continuada de professores recém-ingressos impactou a ação pedagógica em sala de aula? Referencia-se na abordagem qualitativa, delineada pelo estudo de caso, com foco na investigação do trabalho docente de um grupo de treze professores egressos do curso, na busca por indícios que legitimassem a aplicação de saberes e práticas derivados da referida experiência formativa. Estabelece-se interface com as teorias que abordam saberes da docência no ensino superior, processos formativos para a profissionalização docente e o potencial formativo dos ambientes virtuais de aprendizagem (AVA). Na análise da prática pedagógica do grupo de professores, os dados evidenciaram a aplicação de aspectos teórico-metodológicos que se configuram como saberes docentes inovadores, sinalizando uma crescente reconfiguração da ação pedagógica na educação superior. Desse modo, o estudo apresenta, portanto, aspectos didático-pedagógicos potencializados pela formação continuada e incorporados na ação docente de um grupo de professores universitários egressos.
\end{abstract}

PALAVRAS-CHAVE: Educação superior. Docência. Formação continuada. Ação pedagógica.

\section{ABSTRACT}

This work analyzes the impact of a professional updating course on the pedagogical action of university professors. The course represents an action of the professor training program of a public university in the Northeast of Brazil. The study aimed to know how did the continued formation of newly admitted teachers impact the pedagogical action in the classroom. The qualitative approach was the reference of this research, outlined by the case study focused on the investigation of the teaching work group of thirteen professors graduating from the course searching for evidence that would legitimize the application of knowledge and practices derived from said training experience. This work establishes an interface with theories that deal with teaching knowledge in higher education, formative processes for teacher professionalization and the formative potential of Virtual Learning Environments (VLE). In the analysis of the pedagogical practice of the professors' group, the data evidenced the application of theoretical and methodological aspects configured as innovative teaching knowledge, signaling a growing reconfiguration of pedagogical action in higher education. Therefore,

\footnotetext{
${ }^{1}$ Mestre em Educação - Universidade Federal de Alagoas (UFAL) - Maceió, AL. Brasil. Pedagoga - Pró-Reitoria de Graduação Universidade Federal de Alagoas (UFAL) - Maceió, AL. Brasil. E-mail: veralpontess@gmail.com ${ }^{2}$ Doutora em Educação - Université de Provence Aix-Marseille I - Paris, França; e em Linguística Universidade Federal de Alagoas (UFAL) - Maceió, AL. Brasil. Professor Associado I - Centro de Educação da Universidade Federal de Alagoas - Programa de Pós-Graduação em Educação Brasileira - Pesquisa em Tecnologias da Informação e Comunicação na Educação (PPGE) - Universidade Federal de Alagoas (UFAL) - Maceió, AL. Brasil. Email: cleidejanesa@gmail.com
} 
the study presents didactic-pedagogical aspects potentiated by the continued formation and incorporated in the teaching action of a group of university professors graduated.

KEY WORDS: College education. Teaching. Continuing education. Pedagogical action.

\section{RESUMEN}

En este artículo se analiza el impacto de un curso de desarrollo profesional para la acción pedagógica de los profesores universitarios. El curso es una acción del programa de formación de profesores en una universidad pública en el noreste. El estudio tiene el interés de saber: como la formación continua de los profesores universitarios de primer año impactó la acción pedagógica en el aula? Desde un enfoque cualitativo, esbozado por el estudio de caso, se centra en la investigación de la enseñanza de un grupo de trece profesores graduados del curso, en la búsqueda de pruebas para legitimar la aplicación de conocimientos y prácticas derivadas de dicha experiencia de formación. Establece una interfaz con las teorías que se ocupan de la enseñanza de los conocimientos en la educación superior, los procesos de formación de profesionalismo docente y el potencial educativo de los ambientes virtuales de aprendizaje (AVA). En el análisis de la práctica pedagógica del grupo de maestros, los datos mostraron la aplicación de los aspectos teóricos y metodológicos que se configuran como saberes docentes innovadores, lo que indica una reconfiguración creciente de la acción pedagógica en la educación superior. El estudio tiene, pues, aspectos didácticos y pedagógicos mejorados por la formación continua e incorporadas en la actividad de enseñanza de un grupo de profesores universitarios.

PALABRAS CLAVE: Educación universitaria. Enseñanza. Educación continua. Acción pedagógica.

\section{INTRODUÇÃO}

A construção do conhecimento é um processo complexo que pressupõe a interação com outros saberes em diferentes contextos de aprendizagem. Por vezes, será preciso reinventar caminhos, redimensionar percursos, desconstruir o objeto para, depois, reconstruí-lo. Segundo Freire (1996), a aprendizagem é um processo contínuo que deve ser fundado no conhecimento recíproco e motivado por uma vivência cooperativa e transformadora, devendo ser construído sob o viés de múltiplos saberes, de olhares críticos, éticos e autônomos.

Referenciamo-nos nessa premissa freiriana para desconstruir incertezas que nos inquietam e nos incitam ao pensamento reflexivo: o que acontece quando professores universitários de diferentes áreas temáticas se reúnem em um espaço formativo e compartilham conhecimentos plurais e experiências singulares? O contexto no qual esses saberes se consolidam favorece o pensamento crítico e autônomo? Qual o impacto dessa interculturalidade científica e pedagógica ao trabalho docente do professor universitário? São questões que despontam do olhar investigativo na busca por formulação de respostas.

Ao se considerar a educação superior como espaço privilegiado de construção de múltiplos conhecimentos, caracterizado pela formação de profissionais em áreas específicas do conhecimento e pela produção intelectual voltada ao desenvolvimento da ciência, da tecnologia, da cultura e do pensamento reflexivo, segundo prevê a Lei de Diretrizes e Bases da Educação Nacional - LDBEN (BRASIL, 1996), pode-se antever a riqueza e complexidade dos processos de ensino-aprendizagem que se materializam e se disseminam nesses lócus. Nos termos dessa lei, a atividade docente, ao se constituir na complexidade desse cenário 
pluridisciplinar, não deve ocorrer dissociada da articulação entre ensino, pesquisa e extensão, tampouco da articulação teoria e prática, da interdisciplinaridade, da flexibilização, da autonomia, da ética e da responsabilidade social. Além de transcender uma educação tradicional, essas interfaces propõem um referencial inovador para o processo de ensino e aprendizagem na educação superior.

Frente a isso, a realidade assinala um dos desafios do ensino universitário, que é a legitimidade do exercício docente por bacharéis, mestres e doutores em uma área específica do conhecimento, mas sem nenhuma formação oficial para a docência. Esse assunto tem desencadeado amplos debates, no sentido da profissionalização docente universitária como atividade que pressupõe a apropriação de saberes próprios e específicos, assim como ocorre em outros ofícios. Entretanto, ainda há muito a se discutir nesse campo, especialmente pela atividade-fim da educação superior, que é a produção e disseminação de saberes científicos, finalidade essa que justifica a presença de pesquisadores de elevados graus acadêmicos.

A necessidade de aprofundamento desses pressupostos leva-nos a considerar a interface com a literatura que trata da relação entre docência na educação superior e formação continuada, do potencial formativo dos AVA (RAMOS, 2010; MASETTO, 2012; VEIGA, 2010; PIMENTA e ALMEIDA, 2011; PIMENTA e ANASTASIOU, 2010; BEHAR, 2009; SILVA, 2012) e da LDBEN (BRASIL, 1996), as quais abordam a importância de o professor da educação superior se qualificar em uma área científica específica, sendo isto indiscutível. Mas, que também constatam que essa qualificação, no caso do professor em pleno exercício profissional, deve estar associada a processos contínuos de atualização profissional que contemplem, entre outros temas, os saberes pedagógicos, já que foram negligenciados na formação inicial (graduação) e na pós-graduação.

No que compete à exigência de formação pedagógica para o exercício docente na educação superior (PIMENTA; ALMEIDA, 2011), a própria LDBEN (BRASIL, 1996) contribui para secundarizar o ensino ao exigir, exclusivamente, a formação de mestre e/ou doutor em uma área específica do campo científico, não contribuindo com a valorização da competência pedagógica como pré-requisito para o exercício docente nas Instituições de Ensino Superior (IES).

Nesse enfoque, destacamos um Programa de formação continuada em docência do ensino superior (Proford) de uma IES pública do Nordeste que visa à formação permanente de seus professores. Uma das ações formativas desse programa é o curso "Sala de Aula: espaço de mediação pedagógica e de abordagem hipertextual" (Empah), realizado em 2014, no campus Aristóteles Calazans (A.C. Simões), para professores recém-admitidos na instituição. É na curiosidade epistemológica desse espaço formativo que se originou nosso problema de pesquisa, qual seja: como o Empah, curso de formação continuada, contribuiu com a ação pedagógica de um grupo de treze professores recém-ingressos numa IES pública? 
Tomando-se como recorte o curso $\mathrm{Empah}^{3}$, tem-se como fim a investigação das contribuições desse curso à ação pedagógica de professores universitários. Nessa dialética, o estudo se configura como pesquisa qualitativa, delineada pelo estudo de caso, sob o viés da análise de dados empíricos, produzidos por meio da aplicação de questionário e da análise do plano de ensino do grupo de professores egressos. Realiza-se interface com as teorias que tratam da docência no ensino superior, da formação continuada e do potencial formativo dos AVA. A análise dos dados incidiu em importantes contributos teóricometodológicos que convergem para uma emergente reconfiguração de concepções e práticas, proporcionada pelo teor didático-pedagógico da formação.

Buscando situar a problematização deste estudo no contexto da docência universitária e suas implicações, este artigo se desdobra em três seções basilares, além desta introdução e das considerações finais: 1) Docência e formação continuada de professores universitários, que traz um diálogo sistemático sobre concepções, desafios e perspectivas; 2) Para além da sala de aula presencial: integrando cenários na formação de professores, que destaca as possibilidades de interação e mediação pedagógica constituídas no AVA do Empah; e, por fim, 3) A ação pedagógica dos professores egressos da formação continuada, que evidencia as contribuições da formação continuada à prática pedagógica do grupo de professores.

Assim, debruçamo-nos a abordar, metodicamente, os resultados que contribuíram para responder à questão-problema, evidenciando indícios de saberes e fazeres pedagógicos construídos durante a formação continuada e, posteriormente, aplicados pelo grupo de professores ao trabalho docente.

\section{DOCÊNCIA E FORMAÇÃO CONTINUADA DE PROFESSORES UNIVERSITÁRIOS}

No contexto da universidade brasileira, a formação acadêmica de profissionais em áreas específicas do conhecimento é uma das funções da educação superior, e deve se desenvolver em sintonia com as inovações didáticas, científicas, tecnológicas e do mundo do trabalho. Para atuar nesse contexto de múltiplas inovações, os professores devem se atualizar continuamente, haja vista a lacuna pedagógica deixada pela formação inicial e a necessidade de reconfiguração do papel docente em face da sociedade tecnológica (PIMENTA; ALMEIDA, 2011; PIMENTA; ANASTASIOU, 2010).

Na visão de Pimenta e Almeida (2011, p. 24-25), o professor universitário é "aquele que domina o conhecimento específico de sua área ou disciplina, mas que não necessariamente sabe ensinar". Segundo as autoras, a preparação do futuro professor para o cotidiano acadêmico ocorre geralmente em programas de pós-graduação stricto sensu, sob os quais são desenvolvidos conhecimentos teóricos e instrumentais do campo científico de atuação, em detrimento dos saberes pedagógicos, necessários a uma docência adequada.

\footnotetext{
${ }^{3}$ Trata-se de uma ação de formação continuada promovida pelo Programa de formação continuada em docência do ensino superior de uma universidade pública do Nordeste para os docentes recém-admitidos.
} 
De acordo com Zabalza (2004, p. 111), "ensinar é uma tarefa complexa na medida em que exige um conhecimento consistente acerca da disciplina", ao mesmo tempo em que implica "uma sólida formação, não apenas nos conteúdos científicos próprios da disciplina, como também nos aspectos correspondentes à sua didática e ao encaminhamento das diversas variáveis que caracterizam a docência". Essa complexidade do trabalho docente, sobretudo no ensino superior, sugere o repensar dos processos formativos dos professores universitários.

Bolzan, Isaia e Maciel (2013) destacam que a formação em docência pressupõe a organização de um processo contínuo e sistemático que considere as exigências sociais, psicológicas, pessoais, contextuais e profissionais como parte do desenvolvimento profissional docente. Veiga (2010, p.18) endossa esse pensamento quando aponta que a docência é "uma prática social que, para ser problematizada, compreendida e transformada, precisa ser dialogada e construída" mediante os significados que emergem das práticas dos professores e estudantes que a concretizam.

Por sua vez, Masetto (2012) destaca que os saberes didático-pedagógicos que devem ser apropriados pelos professores em exercício profissional são: o conceito de ensinoaprendizagem, a concepção e a gestão do currículo, a complexidade da relação professorestudante e estudante-estudante no processo e, finalmente, a teoria e a prática básicas da integração das Tecnologias Digitais da Informação e Comunicação (TDIC) à educação.

Para Moran (2008), ao invés de repetir o que já está nos livros e nos vídeos, o professor precisa se reconhecer como um orientador dos processos de aprendizagem, que incluem interpretar textos, contextualizá-los, relacioná-los com a vida, com o nosso futuro, profissão, com a nossa prática. Pode ministrar algumas aulas expositivas, em momentos especiais, mas não habitualmente. Na visão do autor, o foco é a orientação, o questionamento, a motivação, o apoio, a ajuda aos que têm mais dificuldades, o acompanhamento de todas as etapas, a síntese e a avaliação continuada.

De acordo com Palfrey e Gasser (2011), os jovens que estão se tornando estudantes na educação superior, ingressando na força de trabalho, vivem grande parte de suas vidas online, sendo diferentes de nós em muitos aspectos. Os autores caracterizam esses jovens como nativos digitais, por se tratar de uma geração que não tem que reaprender nada para viver suas vidas de imersão digital. "Eles começaram a aprender na linguagem digital; só conhece o mundo digital", pontuam Palfrey e Gasser (2011, p. 14). Em meio a essas constatações, observa-se a necessidade de atribuir novos significados à formação do professor no que concerne à atuação frente às TDIC e às novas possibilidades de ensino e aprendizagem.

Ressalta-se que a inovação na sala de aula pressupõe a reconfiguração da prática docente que, por sua vez, pode ser auxiliada por ações formativas que tenham como princípios a reflexão, a interação e o partilhar de saberes que contribuam ao fortalecimento dos encaminhamentos das diversas variáveis que caracterizam a docência. Dada a ausência de formação própria e específica para o exercício da docência, reforça-se a necessidade de 
um processo contínuo de formação docente universitária que deve se configurar como ação permanente nas IES.

\section{Formação docente universitária na perspectiva continuada}

Praticamente, a formação continuada do professor da educação superior somente é acenada no art. 63 da LDBEN, quando se define que as IES deverão manter "programas de formação continuada para os profissionais de educação dos diversos níveis". Posto isso, verifica-se que a legislação nacional de educação não estabeleceu parâmetros específicos para a continuidade da formação docente universitária, apenas sugerindo que essa política seja implementada pelas IES a seus respectivos professores (BRASIL, 1996).

A partir da primeira década do século 21, é possível evidenciar algumas políticas de formação continuada de professores da educação superior em várias IES brasileiras, a exemplo da Universidade Federal do Ceará (UFC), que instituiu a Comunidade de Cooperação e Aprendizagem Significativa (Casa), fundado em 2009, por iniciativa da PróReitoria de Graduação (Prograd), no contexto da expansão e interiorização da educação superior. Do mesmo modo, o Programa formação para a docência no ensino superior da Universidade Federal de Goiás (UFG), além do Programa institucional de formação para a docência no ensino superior da Universidade Estadual de Ponta Grossa (UEPG), ambos instituídos em 2009 e vinculados às respectivas Pró-Reitorias de Graduação, dentre outros.

No IES lócus dessa pesquisa, evidencia-se o Programa de formação continuada em docência do ensino superior (Proford), vinculado à Prograd, regulamentado pela Resolução no 7, de 17 de março de 2014, que passou a integrar o cenário político nacional de formação continuada de professores universitários.

Investir na qualificação profissional dos professores é imprescindível para o desenvolvimento científico e tecnológico das IES, do mesmo modo que é extremamente relevante o domínio dos saberes didático-pedagógicos (ROSEMBERG, 2002; MORAN, 2013). Em vista disso, não se deve negligenciar a formação continuada aos professores da educação superior, haja vista que é esse processo que os permite apropriar-se das inovações pedagógicas necessárias à reconfiguração da sala de aula como espaço significativo de ensino e de aprendizagem.

Segundo Rosemberg (2002, p. 91), os professores da educação superior são responsáveis em produzir e socializar saberes novos, e, por isso, é imprescindível que estejam se apropriando de informações atuais, com a finalidade de acompanhar a evolução do campo de atuação. Para Ramos (2010, p. 89), faz-se necessário criar um espaço que contribua para desconstruir a concepção de professor como profissional de um saber e fornecer elementos estruturantes para que, nesse processo, os professores se compreendam e se assumam como profissionais de ensino.

De acordo com Dias (2010, p. 75), "a docência, bem como a profissão para a qual preparamos o estudante, está imersa numa realidade social em constante mutação, o que 
exige permanente atualização". De outra parte, Leite et al (2012, p. 56) afirma que a formação do professor como um intelectual público "dar-se-á por um processo continuado de intervenções a acontecer de forma sistêmica, articulada e continuada dentro da própria instituição", devendo contemplar sempre a dimensão pedagógica no sentido do formativo e do educativo.

Nesses termos, caminhar pari passu com as exigências educacionais, cujas mudanças se expressam nas reformas político-pedagógicas que transcorrem nas IES em todo Brasil, é um dos grandes desafios da educação superior. Como importante mentor dos processos formativos acadêmicos, o professor da educação superior necessita estar em sintonia com essas mudanças por intermédio de sua participação em programas de formação continuada.

\section{Proford: o novo percurso a ser trilhado por professores universitários}

O Proford é um programa institucional ${ }^{4}$ que tem por finalidade a formação continuada de docentes universitários, inclusive os que atuam na gestão institucional. Possui duas linhas de formação: docência e gestão. Nesses termos, o programa está a contribuir na ressignificação da política de inserção, recepção e ambientação de professores recémadmitidos ${ }^{5}$, pela integração de atividades didático-pedagógicas ao Programa de Inserção do Novo Servidor (Pins) ${ }^{6}$, anteriormente inexistentes. A priorização da dimensão pedagógica na programação do Pins resultou na oferta semestral do curso híbrido Empah, objeto deste estudo.

Sob essa dimensão, o Proford passou a promover atividades em formatos diversos, como roda de conversa, mesa redonda, painel, oficinas, palestra e cursos específicos de atualização didático-pedagógicas, conforme se observa no Quadro 1. A integração de espaços presenciais e online incide num aspecto inovador, sobretudo no Empah. Tal medida favoreceu a flexibilização do tempo e do espaço, a reflexão e a construção de saberes, além da vivência cooperativa da docência.

Com a implementação do Proford, a formação docente universitária foi um fator que ganhou relevância na IES, tendo em vista a observância de ampliação das ofertas formativas, caracterizadas pela diversidade no formato e nos eixos temáticos das atividades. Esses aspectos, somados ao fato de que, anteriormente, não havia ações sistemáticas nesse sentido, vêm configurar um novo caminho na constituição de saberes e práticas docentes no ensino superior. O quadro 1 ilustra os eventos formativos promovidos em 2014, ano que marcou o efetivo início dessa política na IES.

\footnotetext{
${ }^{4}$ Regido pela Resolução Consuni n. 7/2014.

${ }^{5}$ Conforme art. 24, inciso V, da Lei n. 12.772, de 28 de dezembro de 2012, que dispõe sobre a estruturação do Plano de Carreiras e Cargos de Magistério Federal.

${ }^{6} \mathrm{O}$ Pins é um programa institucional que tem por objetivo inserir, recepcionar e promover a ambientação dos servidores recém-empossados à universidade. É composto por $20 \mathrm{~h}$ de atividades, dentre as quais, rodas de conversa, palestras e painéis específicos.
} 
QUADRO 1 - Formações promovidas pelo Proford - 2014.

\begin{tabular}{|l|c|}
\hline \multicolumn{1}{|c|}{ Ações formativas } & Participantes \\
\hline Roda de conversa: Compartilhando docência na IES - Pins & 97 \\
\hline Painel: Inovações metodológicas no ensino superior - Pins & 55 \\
\hline Curso: Sala de aula: espaço de mediação pedagógica e abordagem hipertextual-Pins & 39 \\
\hline Oficina: atualização pedagógica em Ciências Agránias & 39 \\
\hline Painel: Prática pedagógica como componente curricular & 63 \\
\hline $\begin{array}{l}\text { Oficina: Avaliação de cursos, novo instrumento de avaliação e a função da CPAnesse } \\
\text { contexto }\end{array}$ & 58 \\
\hline Minicurso: Formação de Membros do NDE & 15 \\
\hline Curso: Gestão universitánia para os novos diretores de unidade aca dêmica & - \\
\hline Mesa: Debate Intemacional sobre formação docente universitánia - Caïte & - \\
\hline $\begin{array}{l}\text { Mesa: Ofertas de vagas no ensino superior de Alagoas: desa fios e perspectivas no contexto do } \\
\text { PNE - Caiite }\end{array}$ & - \\
\hline Painel: Estágio nas licenciaturas: possibilidades, desafios, práticas inovadoras - Caiite & - \\
\hline $\begin{array}{l}\text { Painel: Estágio nos bacharelados enas formações técnicas e tecnológicas: possibilidades, } \\
\text { desafios e práticas inovadoras - Caüte }\end{array}$ & 366 \\
\hline Total & \\
\hline
\end{tabular}

Fonte: Proford (2014).

O ano de 2014 foi marcado pela implementação do Proford, evidenciando-se uma ampla oferta de eventos formativos, tanto em docência quanto em gestão, o que motivou 366 docentes a aderirem ao programa. Nesse rol de ofertas, destaca-se a primazia do Debate sobre formação docente universitária, que foi enriquecido com a participação de doutores da Universidad Nacional de Córdoba (Argentina), da Universidad de la Republica (Uruguai) e das Universidades Federais de Pernambuco e de Alagoas (Brasil), configurando, assim, um evento internacional. O objetivo desse evento foi estabelecer um intercâmbio que propiciasse um diálogo articulado sobre a formação continuada de professores como elemento inerente à atividade docente.

No âmbito da docência, ressalta-se a roda de conversa que compartilhou questões da docência na perspectiva do ensino, pesquisa e extensão, o painel sobre inovações metodológicas e o curso "Sala de aula: espaço de mediação pedagógica e abordagem hipertextual", que integraram as atividades do Pins. Com isso, iniciou-se uma nova formatação da política de inserção do servidor docente, com priorização da dimensão pedagógica na programação de acolhimento, inserção e formação de professores recémempossados. Os temas pedagógicos priorizados incidiram em: intercâmbio de experiências docentes, inovações metodológicas e mediação pedagógica.

O Empah se constituiu como atividade pedagógica precursora desenvolvida para professores iniciantes, no âmbito do Proford. Por seu caráter flexível e didático, o curso representou uma ação inovadora, marcando, institucionalmente, um novo percurso, a ser trilhado por professores em exercício profissional que buscam a continuidade da formação docente universitária.

\section{PARA ALÉM DA SALA DE AULA PRESENCIAL: INTEGRANDO CENÁRIOS NA FORMAÇÃO DE PROFESSORES}

A necessidade da permanente formação docente universitária tem provocado as IES a encontrarem o caminho para a efetividade da formação continuada de seus professores. $E$ o 
desafio é atender à necessária formação didático-pedagógica do professor, com flexibilização de tempo e espaço para a realização dessas atividades formativas, tendo em vista que esse profissional da docência vive imerso nas mais distintas tarefas acadêmicas relacionadas ao ensino, pesquisa, extensão, gestão, e ainda precisa encontrar tempo para se atualizar profissionalmente.

Nesse sentido, uma das alternativas encontradas pelas IES para viabilizar os processos formativos é a utilização de diferentes lócus de formação, que podem ser caracterizados por interfaces presencial, online ou semipresencial, individual ou em grupo. Um cenário que se caracteriza pelas múltiplas possibilidades pedagógicas é o AVA do Moodle, podendo, numa perspectiva inovadora, configurar-se como um recurso potencial na constituição de saberes docentes para o ensino superior.

Segundo Behar (2009), a Educação a Distância (EaD) pode ser definida como uma forma de aprendizagem organizada, cuja característica básica é a separação física entre quem ensina e quem aprende, além da existência de algum tipo de tecnologia de mediação para estabelecer a interação entre eles. Nessa direção, as Diretrizes e Normas Nacionais para a oferta de Programas e Cursos de Educação Superior ${ }^{7}$ caracterizam a EaD como modalidade educacional na qual a mediação didático-pedagógica, nos processos de ensino e aprendizagem, ocorre com a utilização de meios e tecnologias de informação e comunicação (BRASIL, 2016).

Essa legislação também prevê a descrição dos modelos tecnológicos e digitais, materializados em AVA multimídia interativo, adotados pelas IES, em consonância com os referenciais de qualidade e normas nacionais da $\mathrm{EaD}$ e nos documentos institucionais e acadêmicos, como o Plano de Desenvolvimento Institucional (PDI), o Projeto Pedagógico Institucional (PPI) e o Projeto Pedagógico de Curso de Graduação (PPC), cujo detalhamento deve favorecer maior articulação e efetiva interação e complementariedade entre a presencialidade e a virtualidade, a subjetividade e a participação democrática nos processos de ensino e aprendizagem.

Na sala de aula online, o aprendiz "se engaja em um pensamento ativo, construtivo e intencional, desenvolvendo habilidades de pensamento crítico" e complexo, uma vez que se trata de um processo pedagógico em que há interação, conforme Filatro (2008, p. 110). A autora acresce que essa interação é fundamental ao processo pedagógico, uma vez que pressupõe múltiplas respostas cognitivas e pedagógicas, que resultam em conhecimento construído, produto da dinâmica ensino-aprendizagem.

De acordo com Bastos (2014), o AVA tem característica de software livre que abriga objetos unificados no Padrão Scorm e se constitui como mediação tecnológica da Universidade Aberta do Brasil (UAB). Na visão desse autor, o Moodle apresenta características sociais, cognitivas e pedagógicas, dentre as quais, destacamos: a)

\footnotetext{
${ }^{7}$ Resolução CNE/CES n. 1, de 11 de março de 2016.
} 
construcionista, que permite diálogos e ações, a exemplo do diário de bordo, lições e exercícios; b) colaborativa, estabelecida por meio de wiki, glossário e laboratório de avaliação; e c) comunicacional, construída a partir dos fóruns, chats e mensagens.

Considerando o desenvolvimento do curso Empah, enfatizam-se algumas características presentes no trabalho pedagógico por meio dos espaços virtuais, a saber: a) planejamento das etapas, definição da metodologia adotada e dos critérios de avaliação; b) parceria e coparticipação entre formador e formando no processo de aprendizagem; c) incorporação das inovações pedagógicas como desafio da reconfiguração de saberes na docência da educação superior; d) inovação na sala de aula com uso de instrumentos midiáticos, provocando rupturas na forma de ensinar e aprender; e e) instalação de processo de interação e comunicação no ensino superior (MORAN, 2013).

\section{Empah: o lócus da formação}

Com base em princípios norteadores como a construção colaborativa, a cooperação, o diálogo, o respeito mútuo, a diversidade, a autoria e a cocriação (SILVA, 2012; BEHAR, 2009), que se fazem presentes tanto na sala de aula online como no ensino-aprendizagem face a face, as contribuições da base teórica nos levam, finalmente, para o foco principal deste estudo, que é evidenciar a análise das contribuições da formação continuada de professores recém-ingressos à ação pedagógica em sala de aula por meio do curso Empah.

O curso Empah consiste numa ação de formação continuada construída para os professores recém-ingressos, pela compreensão da dinamicidade dos processos científicos e tecnológicos da educação superior e pela constatação de que esses profissionais não foram contemplados, em sua formação inicial, com as questões didático-pedagógicas. Com hospedagem no AVA do Moodle, desdobrou-se em 30 horas de estudos online e 20 horas de estudos face a face, sinalizando um modelo híbrido de aprendizagem. A flexibilização em aulas online se fundamenta na necessidade de os professores vivenciarem o AVA, visto que a utilização de $20 \%$ da carga horária da graduação em atividades online está prevista na Portaria no. 1.134, de 10 de outubro de 2016, do Ministério da Educação do Brasil.

A partir das interfaces desse curso, construiu-se um debate em torno de questões epistemológicas do fazer pedagógico, utilizando uma comunicação interativa em situações presenciais e online, de modo a possibilitar a socialização de saberes, experiências e reflexões mútuas. $O$ fórum caracterizou-se como importante interface para a reflexão e a construção colaborativa do conhecimento, a partir do qual os professores em formação puderam dialogar sobre diferentes concepções pedagógicas que orientam o ensinoaprendizagem na educação superior.

Dentre os objetivos do curso, destacamos: ampliar a visão teórico-metodológica de apropriação das TDIC como ferramentas que auxiliam e potencializam o processo de ensinoaprendizagem. No encalço dos objetivos da formação, foram desenvolvidos os conteúdos e procedimentos metodológicos abaixo relacionados: 
* Reflexão sobre a pedagogia universitária, a sala de aula, as estratégias didáticas e os processos de aprendizagem no ensino superior;

* Reflexão sobre a avaliação da aprendizagem como processo de investigação do ato pedagógico;

* Vivência de situações por meio de técnicas de ensino, promovendo a pesquisa e a aprendizagem em sala de aula no ensino superior;

* Reflexão sobre a interação e a mediação pedagógica em sala de aula;

* Posicionamento crítico acerca das concepções que fundamentam a prática avaliativa, aliadas aos novos paradigmas e à Web 2.0;

* Discussão sobre os fundamentos que caracterizam a linguagem hipertextual no processo de avaliação da aprendizagem;

* Identificação dos instrumentos e procedimentos de avaliação enquanto processo interativo, de formação e construção do conhecimento;

* Vivência de situações de aprendizagem por meio de procedimentos avaliativos que estimulem a pesquisa e a criatividade, permitindo que os sujeitos sejam interlocutores de seus processos de aprendizagem;

* Construção de mapas conceituais, hipertextos e estudos de casos com base nos saberes da pedagogia universitária;

* Planejamento de uma aula utilizando uma proposta inovadora para a disciplina do professor recém-ingresso, incluindo a avaliação numa abordagem hipertextual.

Numa visão geral, evidencia-se que os aspectos centrais que fundamentaram o curso Empah se respaldam nas variáveis que orientam a prática pedagógica, quais sejam: concepções pedagógicas, processos de aprendizagem, planejamento didático, pressupostos metodológicos, uso pedagógico de recursos online, mediação pedagógica em sala de aula, instrumentos e procedimentos de avaliação. Tais questões nortearam as interações dos professores, tendo como referência a linguagem hipertextual e os novos paradigmas educacionais aliados à Web 2.0. Nesse sentido, o diálogo pedagógico do curso Empah foi constituído com base nos princípios da interação, colaboração e cocriação (SILVA, 2012).

Semelhantemente, constatam-se os recursos tecnológicos, de comunicação, interação e criação que foram mobilizados na proposição e solução das atividades, a saber: o próprio Moodle, Cmap Tools, vídeos, fóruns, chats, mapas conceituais, wiki e plano de ensino. Nessa direção, as reflexões, diálogos e interações promovidos no AVA do Empah serão analisados na seção subsequente, com vistas a dimensionar a relevância dos saberes pedagógicos constituídos no processo formativo, impactados, posteriormente, no trabalho docente em sala de aula. 


\section{A AÇÃO PEDAGÓGICA DOS PROFESSORES EGRESSOS DA FORMAÇÃO CONTINUADA}

A perspectiva da sala de aula como espaço de mediação pedagógica, que utiliza paradigmas inovadores, que pressupõe a interação online e a aprendizagem colaborativa, demanda compreensão e vivência didática das questões que subjazem o ensinoaprendizagem na educação superior. O pensamento criativo gera novos saberes, poder de sintetizar, capacidade de imaginar processos, resultados e possibilidades e de adicionar significado pessoal às informações. Ademais, possibilita a geração de um pensamento complexo, o que permite que se elaborem produtos ou ideias, solucione problemas, tome decisões (FILATRO, 2009; MORAN, 2013).

As discussões teóricas cooperam para se ressaltar que os professores universitários, imbuídos por um esforço coletivo para conhecer, analisar e experimentar os recursos tecnológicos presentes na realidade em que atuam, podem conceber esses aparatos como elementos potenciais ao processo de apropriação, produção e socialização do conhecimento. Essa concepção tende a se fortalecer nos espaços de formação continuada pela presença massiva de elementos didático-pedagógicos próprios da docência, que se interligam por meio da socialização mútua de saberes, experiências, vivências, respaldadas por teorias específicas.

O partilhar de percursos, saberes e práticas

Do ponto de vista didático-metodológico, o percurso do Empah pode ser delineado pela forma como os saberes docentes se constituíram, ou seja, nas situações em que esses saberes se associaram às práticas pedagógicas dos professores egressos. Assim, analisa-se como esses saberes foram mobilizados e didaticamente aplicados na sala de aula, por meio de propostas docentes inovadoras no âmbito profissional. Entende-se, neste estudo, que uma formação alcança seu efeito didático quando seus egressos são capazes de mobilizar os conhecimentos adquiridos no partilhar do percurso formativo para fundamentar sua prática em outros contextos de aprendizagem.

Nesse sentido, apresentamos o relato de professores egressos que projetaram e/ou realizaram situações didáticas no contexto do ensino superior, respaldados pela experiência do Empah, conforme destacam:

Prof11 - [...] a priori, estou utilizando e incentivando o uso do Moodle que foi pouco difundido na minha Unidade Acadêmica. [...] faço uso da Plataforma Moodle como complemento às aulas presenciais.

Prof.9 - Ao finalizar o curso, tentei fazer uma discussão e explorar o AVA [...]. A ideia era fazer a resolução de exercícios comentada com a participação de todos e no ambiente seriam postadas 
todas as respostas encontradas para que a discussão e compreensão ocorresse a partir do que os estudantes postariam. Contudo, falta-me conhecimento e habilidade com essas ferramentas e o que utilizei no curso não foi suficiente para sedimentar esse conhecimento e aplicação em minhas aulas.

Prof.3 - Tenho usado bastante o Moodle, como veículo de informações entre professor-aluno. Mas, ainda preciso incentivar mais o uso desse espaço pelos alunos para uma mediação coletiva.

Prof.10 - [...] obtive boas experiências utilizando [...] a Plataforma Moodle (PROFORD, 2014).

Os relatos docentes anteriormente descritos evidenciam que os egressos propuseram, em suas aulas, o uso pedagógico do AVA do Moodle num ato intencional de transpor os saberes incorporados. Verifica-se a exploração do ambiente online para fins didáticos diversos, entre os quais: envolver a participação dos estudantes na resolução e fomentação de exercícios comentados, veicular informações entre professor-estudante, complementar aulas presenciais. Percebe-se, contudo, um olhar crítico dos próprios professores quanto à aplicação didática do Moodle, uma vez que reconhecem que é preciso aprofundar a apropriação teórica, técnica e pedagógica dos AVA para um uso mais adequado, conforme o seguinte relato: "[...] falta-me conhecimento e habilidade com essas ferramentas, e o que utilizei no curso não foi suficiente para sedimentar esse conhecimento e aplicação em minhas aulas". Essa autoavaliação docente sugere a necessidade de continuidade da formação continuada em nível mais avançado.

Do mesmo modo, os relatos docentes a seguir trazem sobrejacentes a utilização didática dos mapas conceituais, que foi uma das estratégias do Empah para a constituição de saberes pedagógicos:

Prof10 - [...] obtive boas experiências utilizando ferramentas como mapa conceitual [...].

Prof7 - Tentativa de aplicação dos mapas conceituais a partir de alguns textos de revisão teórica numa determinada temática.

Prof2 - Ao longo do segundo semestre de 2014, após o curso, eu utilizei com maior frequência os mapas conceituais. Acho que esse foi um valor agregado desse curso que muito enriqueceu o meu fazer docente.

Prof4 - Incluí a elaboração de mapas conceituais, usando o programa Cmap Tools, como instrumento de avaliação do conteúdo lecionado.

Prof5 - Utilizei mapas conceituais na sala de aula e deu bons resultados.

Prof4 - Acredito que pude melhorar minha abordagem como tutora de PBL (PROFORD, 2014).

Pela própria disposição didática, os mapas conceituais proporcionam uma visão integrada e hierárquica dos conceitos que estão sendo abordados em uma aula, unidade de estudo ou curso (NOVAK E GOWIN, 1996). Em suas narrativas, os professores demonstraram plena habilidade pedagógica ao utilizarem os mapas conceituais como instrumentos de 
revisão teórica e de avaliação de conteúdo. Como instrumento avaliativo, favoreceu a reelaboração de conceitos e sua consequente sedimentação, integração e ampliação dos conhecimentos. Um dos professores faz referência ao curso como estratégia que possibilitou a melhoria da abordagem em PBL [Problem Based Learning], que já utilizava como tutor, destacando-se o aprimoramento pedagógico como um dos princípios do Proford. Em síntese, a ação docente dos egressos revela clara aplicação de saberes e técnicas como valor agregado ao Empah.

Não menos relevante, ressaltamos o relato de um docente que, em sua aplicação didática, transcende os conhecimentos adquiridos em sua formação, evidenciando-se um pensamento crítico, criativo, inovador e complexo.

Prof.12 - Fiz a experiência em analisar um projeto da área em que atuo de trás para frente, ou seja a partir de um projeto já construído, desconstruí-lo e entender seu significado de forma desconstrutivista, ou seja, de trás para frente, da obra até o esboço entendendo a cabeça do profissional que projetou o projeto. Isso possibilitou reflexões diferenciadas pelos estudantes de um mesmo objeto arquitetônico virtual, comum a todos (PROFORD, 2014).

Ao relacionar a aula à concepção pós-estruturalista, que se caracteriza pelo desconstrutivismo, conforme detalhado no relato docente, observa-se uma experiência docente inovadora. Nesta, o professor, motivado pela inteligibilidade do virtual, explora, de forma criativa e interativa, a profundidade do conhecimento em sua área de atuação.

Tendo como referência as variáveis planejamento, metodologia e avaliação, questionou-se ao professor egresso qual a influência da formação continuada (Empah) na ressignificação de concepções e práticas docentes na educação superior. Os relatos docentes revelam que o uso dessas variáveis precede as ações didáticas na IES, mas se intensifica nas ações que se efetivam no fazer docente, após a atualização pedagógica.

Prof.6 - Acredito que as ações consolidaram algumas concepções que já tinha. Tendo em vista que os desafios da prática docente já se apresentavam anteriormente e me impulsionavam a buscar estratégias de atuação.

Prof.2 - [...] a questão que mais me sensibilizou foi quanto à reflexão sobre o que é ser professor nos dias de hoje, no mundo da globalização, das práticas digitais, das redes sociais, enfim, no mundo em que o professor já não mais possui a exclusividade na detenção do saber (PROFORD, 2014).

Dos relatos docentes despontam um posicionamento crítico, consciente e investigativo acerca de concepções pedagógicas que norteiam o ensino universitário, exercendo o princípio reflexivo no âmbito de seu trabalho e das práticas sociais. A ênfase dada à reflexão sobre o papel do professor nos dias de hoje, 'no mundo em que o professor já não mais possui a exclusividade na detenção do saber', demonstra a consciência crítica acerca da compreensão de que é preciso desconstruir e construir a docência.

O planejamento didático consiste em um dos saberes intrínsecos ao fazer pedagógico, o qual se destaca nas respostas dos professores pesquisados, que caracterizam o grau de 
ressignificação desse saber frente à experiência formativa, como é possível observar a seguir:

Prof.1 - Ações do Proford contribuíram para uma reflexão quanto à preparação e execução do plano de curso.

Prof.2 - Do ponto de vista da minha pratica docente, o planejamento de aulas já era uma rotina de trabalho. Obviamente, o curso ampliou a nossa reflexão sobre a importância dessa prática e a necessidade do seu sempre aprimoramento. Nesse sentido, o curso foi benéfico (PROFORD, 2014).

Essas narrativas contribuem para legitimar esse saber como rotina de trabalho indispensável à efetividade do processo educativo, ao mesmo tempo em que se evidenciou que os professores reconheceram os benefícios da formação como processo que ampliou a reflexão sobre a importância e o aprimoramento do planejamento.

Já em relação à variável metodologia, as narrativas docentes foram intensas, evidenciando um aspecto que se desdobra em múltiplas estratégias pedagógicas com um fim-comum: facilitar os processos de ensino-aprendizagem. Os relatos docentes trazem subjacentes uma busca pela diversidade metodológica, por métodos inovadores que descaracterizem práticas tradicionais de ensino, conforme se verifica:

Prof.3 - Tenho tentado buscar inovação nas aulas, especialmente nos campos de prática. Ministro uma disciplina que tem possibilidade de vivenciar diversas metodologias.

Prof.4 - Foi bom ter contato com as metodologias mais atuais de avaliação e de aprendizagem, coisas que eu tinha pouco conhecimento.

Prof.8 - Tive acesso a metodologias ativas e pude começar a planejar o uso das mesmas nas atividades da disciplina.

Prof.9 - A discussão e ampliação dos conhecimentos a respeito de metodologias diferentes das tradicionais são muito importantes e têm proporcionado uma reflexão a respeito de como organizar minhas aulas e como estabelecer o planejamento, quais conteúdos de fato são essenciais e de que forma posso tornar seu aprendizado mais suave e atrativo, uma vez que ministro disciplinas de Exatas que, pelo grau de dificuldade, encontram certa rejeição por parte dos estudantes.

Prof.10 - Passei a dar mais importância ao planejamento das disciplinas, e também estou fazendo um maior esforço para diversificar minha metodologia e formas de avaliação (PROFORD, 2014).

As percepções docentes contribuíram para qualificar a forma como a formação incidiu na ressignificação da concepção de metodologia no ensino superior. Observa-se, contudo, o olhar curioso dos professores na procura pela inovação das aulas, por meio da adoção de metodologias mais atuais de aprendizagem, à semelhança das metodologias ativas, diferentes das tradicionais. 
Ademais, a contribuição empírica dos professores também evidenciou concepções, desafios e perspectivas com relação aos processos avaliativos, destacando o Proford como cenário que auxilia na reconstrução desses processos, conforme se elenca:

Prof.7 - Com o Empah foi possível visualizar novas metodologias de avaliação, assim como de ensino, o que contribuíram para o meu desenvolvimento.

Prof.11 - O Empah inspirou-me a melhorar o método de avaliação que consistia em uma prova escrita apenas. Agora além da prova escrita, há também atividades extraclasses em grupo (solucionar problemas). Minha metodologia melhorou, pois além da lousa tenho usado o Moodle como ambiente de debates para fazer simulações de experiências na disciplina que ministro.

Prof.12 - O Proford ajudou mais na parte metodológica (exemplo: mapas mentais) e, na avaliação, principalmente utilizando novas mídias (vídeos, hipertextos e imagens), sobretudo porque trabalho muito com imagens e projetos.

Prof.9 - A forma de fragmentar as avaliações, de incluir novas opções além da prova tradicional tem sido proposta no intuito de estimular e auxiliar o aprendizado de forma continuada sem a necessidade da "barganha" pela nota. [...]

Prof.13 - Contribuiu com a avaliação, pois antes a nota era alicerçada em provas, somente. Hoje, faço trabalhos para somar com a prova. Mas, ainda tenho um alto índice de reprovações e desistências (PROFORD, 2014).

A partir do exposto, lançam-se os aspectos que motivaram o posicionamento reflexivo e a mudança da concepção dos professores no que se refere à avaliação. A busca por novas formas de avaliar, auxiliadas por novas mídias, mapas conceituais, hipertextos, vídeos, imagens, trabalhos, no sentido de uma avaliação contínua e formativa, foi fator preponderante nas citações dos professores.

Em síntese, é possível dimensionar os aspectos de maior peso para os professores na vivência com a sala de aula da formação continuada os quais favoreceram a ressignificação do discurso e da prática pedagógica dos egressos. Em sua maioria, os professores demonstraram reconhecer, dentre outras questões, que o Proford contribui para uma reflexão quanto à preparação e a execução do plano de ensino, visualização de metodologias atuais de ensino e de avaliação, além da consolidação de concepções pedagógicas.

De forma didática e sistemática, a Figura 1 sintetiza os saberes pedagógicos evidenciados pelos professores mediante sua participação ativa no curso Empah:

FIGURA 1 - Esquema-síntese das potencialidades pedagógicas do curso EMPAH 


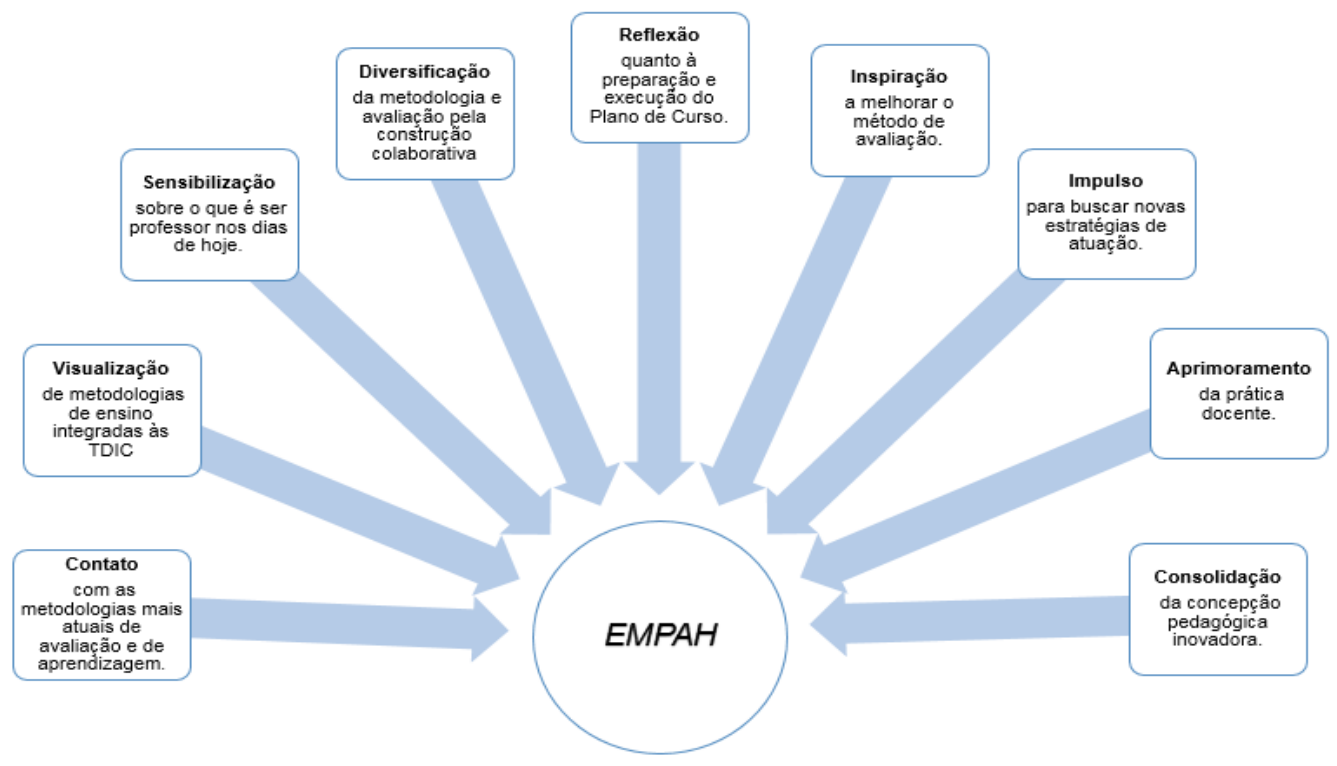

Fonte: Santos (2016) - Dados da Pesquisa.

Os saberes que se apresentam na Figura 1 caracterizam uma nova perspectiva pedagógica teórico-metodológica, que concorre para um "ensino inovador", visto que foram problematizados, consolidados e transformados na própria prática docente.

Dessa forma, sintetizam-se os saberes pedagógicos evidenciados nas relações cognitivas e pedagógicas estabelecidas entre formadores, cursistas e os conhecimentos e procedimentos sistematizados no cenário do Empah, quais sejam: contato, visualização, sensibilização, diversificação, reflexão, inspiração, impulso, aprimoramento e consolidação na constituição de saberes docentes. Esses princípios representam caminhos pedagógicos constituídos pelos professores por meio da interação com outros saberes, com recursos tecnológicos e com os seus pares, os quais convergem para a reconfiguração do discurso e prática docentes.

\section{Ressignificação do plano de ensino dos professores egressos}

O plano de ensino consiste numa ferramenta que reflete o trabalho pedagógico de uma determinada área ou disciplina. Nele, o professor preestabelece aspectos do processo de aprendizagem, como objetivo, conteúdo (ementa), metodologia, estratégia avaliativa, bibliografia básica e complementar, que nortearão as aulas ao longo de um período letivo, que pode ser mensal, bimestral, semestral ou anual.

No entanto, é na prática que reside o maior desafio para o professor, pois é na experiência da sala de aula que precisará ter ampla compreensão dos processos de aprendizagem que subjazem a apropriação do conhecimento, e isto requer a mobilização de saberes didático-pedagógicos. Um plano de trabalho articulado e sistemático, imbuído de intencionalidade pedagógica, pode ser assistencial à visualização prévia dos desafios de aprendizagem. 
$\mathrm{Na}$ perspectiva de uma proposta didática que se fundamentasse no modelo pedagógico do curso Empah, uma das atividades do curso propôs que cada professor cursista elaborasse o seu plano de ensino, sem deixar de considerar os recursos tecnológicos abordados. Tomando como norte a participação ativa dos cursistas no desenvolvimento dessa proposta, buscou-se, neste estudo, identificar se os aspectos didático-pedagógicos construídos durante o percurso formativo estavam traduzidos no plano de ensino do professor egresso e, por consequência, na respectiva ação pedagógica.

Ressalta-se que o planejamento pedagógico foi tema da formação, tanto no que concerne à reflexão, quanto à elaboração do plano de ensino. Os aspectos abordados na elaboração do respectivo plano foram: identificação, ementa, objetivos, conteúdo programático, metodologia, avaliação e referências. Tal abordagem referenciou a definição de critérios na análise dos planos de ensino, além de outros elementos identificados na base teórica, como concepção pedagógica que orienta os processos (ainda que os professores não tenham consciência de sua utilização), estratégias didáticas, instrumentos e procedimentos avaliativos (MASETTO, 2012; PIMENTA; ALMEIDA, 2011; SILVA, 2012; MORAN, 2013), dentre outros elementos identificados no próprio plano de ensino.

O Quadro 2 sintetiza o resultado da análise da disciplina de cada professor participante, norteados pelas variáveis didáticas objetivo, metodologia e avaliação, com vistas a estabelecer uma análise paralela aos relatos docentes, no sentido de ratificar as contribuições do Empah ao processo de ressignificação do trabalho pedagógico do professor universitário. 
QUADRO 2 - Síntese da análise dos planos de ensino dos professores

\begin{tabular}{|l|l|l|}
\hline \multicolumn{1}{|c|}{ Participantes } & Concepção & \multicolumn{1}{|c|}{ Características epistemológicas } \\
\hline Prof.1 e Prof.4 & Tradicional & $\begin{array}{l}\text { Prevalência de aulas expositivas, exercícios de fixação, provas } \\
\text { bimestrais }\end{array}$ \\
\hline $\begin{array}{l}\text { Prof.5, Prof.6, } \\
\text { Prof.11 e Prof.13 }\end{array}$ & Transicional & $\begin{array}{l}\text { Presença de elementos que caracterizam o ensino tradicional } \\
\text { (transmissão do conhecimento), mas, sobretudo, de elementos } \\
\text { inovadores (construção do conhecimento), caracterizados pela } \\
\text { inserção de estratégias diferenciadas, como o diálogo, o uso de } \\
\text { diferentes gêneros textuais para leitura e discussão, seminários, } \\
\text { projetos, orientação individualizada, integração de tecnologias, a } \\
\text { exemplo do AVEA Moodle. }\end{array}$ \\
\hline $\begin{array}{l}\text { Prof.2, Prof.3, } \\
\text { Prof.8, Prof.10 e }\end{array}$ & Inovadora & $\begin{array}{l}\text { Articulação teórico-metodológica marcada por objetivos claros e } \\
\text { bem definidos e por estratégias construtivas e colaborativas, } \\
\text { como diálogos, seminários, simulações de aulas, mapas } \\
\text { conceituais, aulas baseadas em casos, diversidade de textos } \\
\text { literários como suporte reflexivo, elaboração e vivência de } \\
\text { projetos de intervenção, uso de EaD etc. }\end{array}$ \\
\hline
\end{tabular}

Fonte: Autoras (2016) - Dados da Pesquisa.

Os planos de ensino refletem a prática pedagógica dos professores, em diferentes áreas do conhecimento, nos semestres 2015.1 e 2015.2, períodos letivos subsequentes ao curso Empah. A análise desses planos possibilitou a evidenciação de indicativos didáticos que concorrem à reconfiguração do fazer docente na educação superior, por meio da ação dos professores em processo continuado de formação, portanto, imbuída de novas perspectivas didático-pedagógicas.

Igualmente, a análise dos planos de ensino nos levou a verificar uma diversidade curricular na apresentação das disciplinas a que se referem os planos, contemplando as mais diversas áreas em que estão situados os cursos de graduação, quais sejam: Ciências Exatas, Engenharias, Ciências Biológicas, Ciências Sociais e Ciências Humanas, as quais contribuem para a riqueza das análises e discussão. A carga horária das disciplinas variou entre $40 \mathrm{~h}, 60 \mathrm{~h}, 80 \mathrm{~h}$ e $100 \mathrm{~h}$, sendo que o formato de $60 \mathrm{~h}$ foi o mais evidenciado.

Constatamos que a docência de dois dos treze professores pesquisados foi fundada numa prática pedagógica tradicional (mesmo com a verificação de "elementos didáticos inovadores" em seus planos de ensino), a exemplo do Prof.4, que centrou sua prática em aulas expositivas e exercícios de fixação, próprios do ensino tradicional. Do mesmo modo, o Prof.1 priorizou a exposição de conceitos em suas aulas, porém desde uma abordagem tradicional, utilizou-se do AVA Moodle como espaço para postagem das respostas de exercícios aplicados, segundo descreveu:

Prof.1 - O Moodle é utilizado como instrumento de avaliação formativa onde o estudante posta uma solução para determinado problema e eu apenas o oriento e corrijo. $O$ Moodle é apenas para estudar, não atribuo nota. Para fins de progressão acadêmica, as avaliações presenciais (provas bimestrais) são o único instrumento avaliativo (PROFORD, 2014). 
Pela sua natureza e funcionalidade, o AVA do Moodle oferece múltiplas possibilidades pedagógicas, indo muito além da hospedagem de conteúdos e de listas de exercícios que visam à memorização de conceitos e fórmulas. Trata-se de um espaço de aprendizagem colaborativa que prevê a interação, a coautoria e a co-construção (SILVA, 2012). Outra questão que se enfatiza é a conotação dada pelo Prof.1 à avaliação formativa, que, diferente da função de observar a aprendizagem dos estudantes e classificá-los, pressupõe a utilização de vários instrumentos avaliativos como forma de analisar o nível de conhecimento da turma com vistas ao planejamento de estratégias de ensino na perspectiva da real aprendizagem (LUCKESI, 2006).

A análise dos planos de ensino dos participantes Prof.5, Prof.6, Prof.7, Prof.9, Prof.11 e Prof.13 indica um processo de transição da concepção tradicional à concepção inovadora. Isso porque, ainda que houvesse a presença de elementos que caracterizam o ensino tradicional (transmissão do conhecimento), identificamos, sobretudo, elementos inovadores (construção do conhecimento) nessas práticas, o que concorrem para mudanças na ação pedagógica dos professores universitários. Em outras palavras, embora a aula expositiva seja um fator circunstanciado no trabalho docente desses professores, a inserção de estratégias diferenciadas, como o diálogo, o uso de diferentes gêneros textuais para leitura e discussão, seminários, projetos, orientação individualizada, integração de tecnologias, a exemplo do AVA Moodle, contribuem à evidenciação de uma emergente mudança pedagógica.

Assim, quando analisamos os planos de ensino dos Prof.2, Prof.3, Prof.8, Prof.10 e Prof.12, em especial, constatamos uma abordagem voltada ao ensino inovador, ainda que se observem resquícios tradicionais, principalmente no uso de instrumentos avaliativos conservadores, como é o caso das provas bimestrais. No entanto, é crescente a articulação teórico-metodológica marcada por objetivos claros e bem definidos e por estratégias construtivas e colaborativas, como diálogos, seminários, simulações de aulas, mapas conceituais, aulas baseadas em casos, diversidade de textos literários como suporte reflexivo, elaboração e vivência de projetos de intervenção, uso de EaD etc. Esses indícios refletem a ação pedagógica que os participantes da pesquisa vivenciaram no curso Empah, que podem ter contribuído para a renovação pedagógica desses professores egressos.

Em resumo, a análise dos treze planos de ensino, considerando os critérios préestabelecidos, resultou na constatação de duas concepções pedagógicas que nortearam o trabalho pedagógico dos professores: a tradicional, orientada pela transmissão de saberes do professor (aquele que sabe) para o estudante (aquele que não sabe), de acordo com Masetto (2012) e Pimenta e Almeida (2011); e a inovadora ${ }^{8}$, guiada pelo uso pedagógico das TDIC, por meio de princípios como construção, colaboração, interação, coautoria, como defendem Moran (2013) e Silva (2012). Ademais, constatou-se uma terceira concepção, que podemos nomear de transitória, relativa à passagem gradual do método tradicional de ensino para o método inovador. A concepção transitória reflete a busca do professor pela ressignificação do trabalho docente.

\footnotetext{
${ }^{8}$ A concepção inovadora é tratada neste estudo numa perspectiva de construção colaborativa do conhecimento com apoio das TDIC, conforme Moran, Masetto e Behrens (2013) e Silva (2012).
} 
Seja numa perspectiva de ensino tradicional, transicional ou inovadora, não podemos deixar de evidenciar que a prova bimestral ${ }^{9}$ é um dos instrumentos avaliativos mais utilizados pelos docentes investigados, tendo em vista que está presente em, pelo menos, $85 \%$ dos planos de ensino analisados, o que apontou, em linhas gerais, para um dos métodos padrão na universidade. Mas, mesmo buscando cumprir as normas do sistema acadêmico institucional, geralmente aplicadas através de provas escritas, emergiram da prática pedagógica de professores que participaram deste estudo, instrumentos avaliativos inovadores, como resenhas, seminários, relatórios, projetos, mapas conceituais, caracterizando também uma mudança gradativa nas formas de avaliar a aprendizagem na educação superior.

Nesse sentido, a análise dos planos de ensino, enriquecido por apontamentos docentes complementares, sinalizam mudanças pedagógica significativas, corroborando para ratificar o Proford como uma política formativa que contribui, de forma progressiva, à ressignificação de processos pedagógicos. Nessa perspectiva, ressalta-se que a experiência dos participantes no curso Empah favoreceu a visão pedagógica no planejamento das disciplinas da graduação.

A partir dos dados analisados, pode-se dizer que as concepções pedagógicas dos professores participantes da pesquisa estão passando por uma transição gradativa, tanto no que se referem aos objetivos didáticos, que vão além da assimilação de conceitos disciplinares, quanto aos procedimentos metodológicos e avaliativos, cujas perspectivas apontam para a construção reflexiva e a colaborativa dos conhecimentos.

\section{CONSIDERAÇÕES FINAIS}

As reflexões acerca da docência na educação superior corroboraram para a compreensão desta atividade como uma profissão, e, como tal, necessita de formação didático-pedagógica. Desta feita, a questão que norteou este estudo - como a formação continuada impactou a ação pedagógica de treze professores universitários recémingressos? - é esclarecida na medida em que se debruçou criteriosamente à análise dos relatos docentes e de seus respectivos planos de ensino, chegando-se a um resultado. $A$ análise da ação pedagógica resultante da formação continuada trouxe-nos indícios claros de melhorias no trabalho docente, desde a reconfiguração de concepções pedagógicas, utilização de metodologias inovadoras, com ou sem integração tecnológica, além de instrumentos e procedimentos inovadores de avaliação da aprendizagem.

As análises tecidas ao longo deste estudo, sejam referenciadas nos aportes teóricos ou fundamentadas nos relatos dos participantes que cursaram o Empah, contribuíram para constatar que há uma crescente reconfiguração do discurso pedagógico. Os professores demonstraram, a partir da vivência e aplicação de inovações relativas à metodologia, ao uso das TDIC e à avaliação do ensino-aprendizagem, que o Empah, pelo seu caráter flexível, didático, interativo e dinâmico, pode ser uma ambiência necessária à formação continuada de professores universitários.

\footnotetext{
${ }^{9} \mathrm{O}$ art. 41 do Estatuto e Regimento Geral da UFAL normatiza a avaliação da proficiência dos estudantes nas diferentes disciplinas da graduação, sendo aferida através de Avaliação Bimestral ( $A B$ ), em número de 2 (duas), por semestre letivo, e Prova Final (PF), para os estudantes que obtiveram rendimento insatisfatório.
} 
Considerando as peculiaridades do ensino superior que têm em seu bojo a formação do cidadão, do profissional e do sujeito sociopolítico, evidenciou-se a importância de o professor considerar as múltiplas possibilidades de interação didática em suas aulas numa perspectiva de ação-reflexão-ação, haja vista que aprendizagens interativas devem pressupor situações didáticas interativas.

A interação dos professores recém-ingressos no AVA do curso, que resultou na (re) construção de saberes pedagógicos, permite-nos destacar que, quando se trata de aprendizagem online, é necessário disponibilizar uma interface que favoreça a produção de novos conhecimentos a partir das interações com conteúdo, ferramentas tecnológicas e com outras pessoas, sob as quais indivíduos e objetos se influenciam mutuamente. Os diversos saberes pedagógicos destacados concorreram para o fortalecimento de cursos que integrem o presencial e o virtual como interfaces que possibilitam interação, colaboração, argumentação, troca de saberes e experiências sobre a égide do ensino e aprendizagem na educação superior.

A proposta de conteúdos e de procedimentos metodológicos do curso Empah priorizou a (re) construção colaborativa do conhecimento por meio de concepções pedagógicas de especialistas em textos, hipertextos e vídeos disponibilizados no próprio AVA do curso, que motivaram a interação dos professores recém-ingressos e o desejo destes em expor suas perspectivas imbuídas de suas vivências e práticas oriundas da própria ação docente.

Por sua vez, as análises das respostas às questões propostas aos participantes deste estudo, bem como a análise dos respectivos planos de ensino do grupo de professores egressos possibilitaram a constatação de um impacto pedagógico favorável do Proford à prática docente. Tais contribuições estão imbricadas na docência dos professores da educação superior, sejam na dimensão dos saberes, sejam na dimensão dos fazeres pedagógicos.

Levando em consideração a complexidade da docência universitária, concordamos que ainda há muito que conquistar no campo da atuação e da investigação da formação continuada. Todavia, temos consciência do quanto é importante prosseguir na contínua busca por um ensino universitário cada vez mais dialético, colaborativo e emancipado, voltado para a construção de amplos conhecimentos científicos, e de que as TDIC podem contribuir como mediadoras desse processo.

Compreendendo que a formação inicial (graduação) e a pós-graduação dos professores da educação superior tem mais inclinação para a pesquisa do que para o ensino, conforme os resultados do curso Empah à prática do professor egresso, reafirmamos a relevância da formação continuada para professores da educação superior, dada a constatação, neste estudo, das contribuições desse processo ao trabalho docente. Assim sendo, destacamos o cenário da sala de aula híbrida, na perspectiva da personalização do ensino, como questão futura a ser investigada, no sentido da formação continuada de professores universitários. 


\section{REFERÊNCIAS}

BASTOS, Fabio et al. Regularidades e Transformações em Hipermídia Educacional. Revista Brasileira de Informática na Educação, v. 22, n. 1, p. 67-78, 2014.

BEHAR, Patrícia. Modelos pedagógicos em educação a distância. Porto Alegre: Artmed, 2009.

BOLZAN, Doris; ISAIA, Silvia; MACIEL, Adriana. Formação de professores: a construção da docência e da atividade pedagógica na educação superior. Rev. Diálogo Educ., Curitiba, v. 13, n. 38, p. 49-68, jan./abr. 2013.

BRASIL. Lei n. 9.394, de 20 de dezembro de 1996. Estabelece as diretrizes e bases da educação nacional. Diário Oficial [da] República Federativa do Brasil, Brasília, DF, 23 dez. 1996. Disponível em: http://www.planalto.gov.br/ccivil 03/Leis/L9394.htm Acesso em: 8 set. 2017.

BRASIL. Resolução CNE/CES n. 1, de 11 de março de 2016. Estabelece Diretrizes e Normas Nacionais para a Oferta de Programas e Cursos de Educação Superior na Modalidade a Distância. Diário Oficial [da] República Federativa do Brasil, Brasília, DF, 14 mar. 2016. Disponível em: http://portal.mec.gov.br/despesas/323-secretarias-112877938/orgaosvincula dos-82187207/34891-resolucoes-cne-ces-2016 Acesso em: 9 set. 2017.

BRASIL. Portaria n. 1.134, de 10 de outubro de 2016. Dispõe sobre oferta à distância de disciplinas dos cursos presenciais. Diário Oficial [da] República Federativa do Brasil, Brasília, DF, 11 out. 2016. Disponível em:

https://abmes.org.br/legislacoes/detalhe/1988/portaria-n-1134 Acesso em: 9 set. 2017.

DIAS, Ana Maria. Leitura e (auto) Formação: caminhos percorridos por docentes na educação superior. In: VEIGA, I. P.; VIANA, C. M. (Org.). Docentes para a educação superior: processos formativos. Campinas: Papirus, 2010, p. 71-100.

FILATRO, Andrea. Design instrucional na prática. São Paulo: Pearson Education do Brasil, 2008.

FREIRE, Paulo. Pedagogia da autonomia: saberes necessários à prática educativa. São Paulo: Paz e Terra, 1996.

LEITE, Denise. et al. A avaliação institucional e os desafios da formação do docente da universidade pós-moderna. In: MASETTO, M. T. (Org.). Docência na universidade. Campinas: Papirus, 2012, p. 41-59.

LUCKESI, Cipriano. Avaliação da aprendizagem escolar: estudos e proposições. São Paulo: Cortez, 2006.

MASETTO, Marcos. Professor universitário: um profissional da educação na atividade docente. In: MASETTO. (Org.). Docência na universidade. Campinas: Papirus, 2012.

MORAN, José Manuel. Ensino e aprendizagem inovadores com apoio de tecnologias. In: MORAN; MASETTO, M. T.; BEHRENS, M. A. Novas tecnologias e mediação pedagógica. 21. ed. são Paulo: Papirus, 2013, p. 11-72. 
MORAN, José Manuel. Formação de educadores inovadores para uma nova escola. Boletim Salto para o Futuro. Brasília, DF, ano 18I, n. 18, p. 40-48, set./out. 2008.

NOVAK, Joseph; GOWIN, Bob. Aprender a aprender. Lisboa: Plátano Edições Técnicas, 1996. Tradução de Learning how to learn. Ithaca, N.Y.: Cornell University Press, 1984.

PALFREY, John; GASSER, Urs. Nascidos na era digital: entendendo a primeira geração de nativos digitais. Porto Alegre: Artmed, 2011.

PIMENTA, Selma Garrido; ANASTASIOU, Léa. Docência no ensino superior. São Paulo: Cortez, 2010.

PIMENTA, Selma Garrido; ALMEIDA, Maria Isabel. Pedagogia universitária. São Paulo: Cortez, 2011.

RAMOS, Kátia. Reconfigurar a profissionalidade docente universitária: um olhar sobre ações de atualização pedagógica-didática. Porto: Porto Editorial, 2010.

ROSEMBERG, Dulcinéa. 0 processo de formação continuada de professores universitários: do instituído ao instituinte. Niterói: Wak, 2002.

SANTOS, Vera Lucia Pontes dos. Docência na educação superior e a ação pedagógica resultante da formação continuada de professores recém-ingressos na Ufal/Dissertação de Mestrado, PPGE da Ufal, Maceió, 2016.

SILVA, Marcos. Sala de aula interativa. São Paulo: Loyola, 2012.

UNIVERSIDADE FEDERAL DE ALAGOAS - UFAL. Resolução no. 07, de 17 de março de 2014. Aprova o Programa de Formação Continuada em Docência do Ensino Superior - PROFORD. Maceió: Consuni UFAL, 2014.

VEIGA, IIma Passos. Alternativas pedagógicas para a formação do professor da educação superior. In: VEIGA; VIANA, C. M. (Org.). Docentes para a educação superior: processos formativos. Campinas: Papirus, 2010. p. 13-28.

ZABALZA, Miguel. 0 ensino universitário: seu cenário e seus protagonistas. Porto Alegre: Artmed, 2004. 